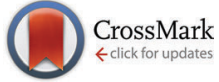

Cite this: J. Mater. Chem. C, 2015, 3, 10534

Received 6th July 2015, Accepted 5th August 2015 DOI: $10.1039 / c 5 t c 02025 e$

www.rsc.org/MaterialsC

\title{
Compositions and thermoelectric properties of XNiSn (X = Ti, Zr, Hf) half-Heusler alloys
}

\author{
R. A. Downie, ${ }^{a}$ S. A. Barczak, ${ }^{a}$ R. I. Smith ${ }^{b}$ and J. W. G. Bos ${ }^{\star^{a}}$
}

\begin{abstract}
Rietveld analysis of neutron powder diffraction data has been used to investigate the compositions of $\mathrm{XNiSn}(\mathrm{X}=\mathrm{Ti}, \mathrm{Zr}, \mathrm{Hf}$ ) half-Heusler alloys prepared by solid state reactions. All samples containing Ti have $2-3 \%$ excess $\mathrm{Ni}$, whereas the samples with $\mathrm{X}=\mathrm{Zr}, \mathrm{Hf}$ are almost stoichiometric. Samples with mixed $\mathrm{X}$-metals are characterised by the presence of 3-4 distinct $\mathrm{X}_{1-x} \mathrm{X}_{{ }_{x}} \mathrm{Ni}_{1+y} \mathrm{Sn}$ half-Heusler phases. Variable temperature and time dependent neutron powder diffraction for $X=\mathrm{Ti}$ and $\mathrm{X}=\mathrm{Ti}_{0.5} \mathrm{Hf}_{0.5}$ demonstrates that both the amount of excess $\mathrm{Ni}$ and the phase distribution are stable up to at least $600{ }^{\circ} \mathrm{C}$. Debye temperatures of 367(2) $\mathrm{K}$ and $317(2) \mathrm{K}$ were obtained from the thermal displacement parameters. The samples containing Ti are characterised by a $\sim 0.15 \mathrm{eV}$ bandgap and a monotonously decreasing Seebeck coefficient. The compositions with $\mathrm{Zr}$ and $\mathrm{Hf}$ have similar bandgap values but show ambipolar transitions. Analysis of the thermoelectric transport data of degenerately doped $\mathrm{Ti}_{0.5} \mathrm{Zr}_{0.5} \mathrm{NiSn}_{1-z} \mathrm{Sb}_{z}$ samples using a single parabolic band model demonstrates that the transport is limited by alloy scattering and yielded an effective carrier mass of 2.5(1) $m_{\mathrm{e}}$.
\end{abstract}

\section{Introduction}

Half-Heuslers (HHs) show great promise in the field of thermoelectric waste heat recovery, in which they can be used to improve the energy efficiency of any heat-generating process. ${ }^{1}$ The performance of a thermoelectric material is determined by its figure of merit, $z T=S^{2} T / \rho \kappa$, where $S$ is the Seebeck coefficient, $\rho$ is the electrical resistivity, $\kappa$ is the sum of the lattice $\left(\kappa_{\text {lat }}\right)$ and electronic $\left(\kappa_{\mathrm{el}}\right)$ thermal conductivities, and $T$ is the absolute temperature. The large power factors $\left(S^{2} / \rho\right)$ possessed by HHs make them an obvious choice for thermoelectrics research, but high $\kappa$ values mean that alterations to the structure must be made to reduce $\kappa_{\text {lat }}$ and achieve high $z T$ values. $^{2-6}$

Recently, phases on the XNiSn- $\mathrm{XNi}_{2} \mathrm{Sn} \mathrm{HH}$ full-Heusler (FH) pseudo-binary have generated substantial interest (where $\mathrm{X}=$ Ti, Zr, Hf). ${ }^{3,5,6}$ The addition of excess Ni has been found to have a significant impact on the thermoelectric properties. In particular, large reductions in the thermal conductivity of $\mathrm{TiNi}_{1+y} \mathrm{Sn}$ samples have been reported. ${ }^{7-13}$ In addition, simultaneously enhanced $S$ and electrical conductivity $(\sigma=1 / \rho)$ was reported for $\mathrm{Zr}_{0.25} \mathrm{Hf}_{0.75} \mathrm{Ni}_{1+y} \mathrm{Sn},{ }^{14}$ and enhanced $S$ with only a minor reduction in $\sigma$ has been found in $\mathrm{Ti}_{0.1} \mathrm{Zr}_{0.9} \mathrm{Ni}_{1+y} \mathrm{Sn}$ and p-type $\mathrm{Ti}_{0.5} \mathrm{Hf}_{0.5} \mathrm{Co}_{1+y} \mathrm{Sn}_{0.9} \mathrm{Sn}_{0.1} \cdot{ }^{15,16}$ Simultaneous improvements in $S$

\footnotetext{
${ }^{a}$ Institute of Chemical Sciences and Centre for Advanced Energy Storage and Recovery, School of Engineering and Physical Sciences, Heriot-Watt University, Edinburgh, EH14 4AS, UK. E-mail: j.w.g.bos@hw.ac.uk

${ }^{b}$ ISIS Facility, Rutherford Appleton Laboratory, Harwell Oxford, Didcot, OX11 oQX, $U K$
}

and $\sigma$ are not expected in homogenous semiconductors, where they depend inversely on carrier concentration. ${ }^{1}$ The observation of this effect therefore suggests that potential barriers, due to FH nano-inclusions, filter out low energy carriers leading to an enhancement of S. ${ }^{17}$ Indeed, the formation of $\mathrm{FH}$ nanoinclusions within the $\mathrm{HH}$ matrix has been reported in many of these studies. ${ }^{8-10,13-16}$ However, not all samples containing excess Ni $(y>0)$ show enhancements of $S$ and $\sigma$, and other reports observe only micro-inclusions of the $\mathrm{FH}$ phase. ${ }^{11,12} \mathrm{We}$ recently reported an in-depth study of $\operatorname{TiNiM}_{y} \mathrm{Sn}(\mathrm{M}=\mathrm{Co}, \mathrm{Ni}$, and $\mathrm{Cu}$ ) nanocomposites prepared via solid state reactions and showed that the excess metal is relatively homogeneously distributed with an upper limit $<2 \mathrm{~nm}$ for any segregated $\mathrm{TiNi}_{2} \mathrm{Sn} \mathrm{FH}$ inclusions. ${ }^{18}$ The absence of clear inclusions demonstrates that the degree of segregation is sensitively dependent on the sample processing, which is in keeping with the wide variety of nanostructures reported in the literature. ${ }^{3,6}$ Another topical issue in this field regards the low $\kappa\left(=2-3 \mathrm{~W} \mathrm{~m}^{-1} \mathrm{~K}^{-1}\right)$ that is sometimes observed in XNiSn and XCoSb samples with mixtures of Ti, $\mathrm{Zr}$ and $\mathrm{Hf}$, and which is important to underpin $Z T>1$. $^{19-23}$ Recent studies have linked the low $\kappa$ to phase segregation into multiple half-Heusler phases with different ratios of X-metals. ${ }^{6,21,24}$ However, our results for the $\mathrm{Ti}_{1-x} \mathrm{Zr}_{x} \mathrm{NiSn}$ series indicate that this multiphase behaviour is kinetically controlled, and has a secondary impact on $\kappa(T)$ after alloy scattering, suggesting that the presence of all three of $\mathrm{Ti}, \mathrm{Zr}$ and $\mathrm{Hf}$ is needed. ${ }^{25}$ Other approaches aimed at minimising $\kappa_{\text {lat }}$ include off-stoichiometric $\mathrm{X}_{9} \mathrm{Ni}_{7} \mathrm{Sn}_{8}(\mathrm{X}=\mathrm{Ti}, \mathrm{Zr})$ compositions that form a $\mathrm{HH}$ matrix and a number of segregated phases, ${ }^{26,27}$ addition 
of a $\mathrm{Ti}_{70.5} \mathrm{Fe}_{29.5}$ eutectic, ${ }^{28}$ InSb inclusions in TiCoSb, ${ }^{29,30}$ and phase segregation involving mixtures of $\mathrm{HH}$ phases. ${ }^{31}$

Neutron powder diffraction is a powerful tool to characterise metal-rich $\mathrm{HH}$ alloys due to the excellent scattering contrast between the elements present. ${ }^{7,18,32}$ In addition, the bulk nature of the technique means a representative average picture is obtained. For the $\operatorname{TiNiM}_{y} \mathrm{Sn}(\mathrm{M}=\mathrm{Co}, \mathrm{Ni}$, and $\mathrm{Cu})$ nanocomposites it was possible to account for all excess metal present in the sample. ${ }^{18}$ In case of the $\mathrm{M}=\mathrm{Ni}$ series, the excess $\mathrm{Ni}$ was divided over the matrix (nano-inclusions with diameter $<2 \mathrm{~nm}$ ) and over a distinct $\mathrm{FH}$ phase with the sum of excess $\mathrm{Ni}$ equal to the nominal y value. This analysis also allowed us to determine that $\mathrm{Co}$ substitutes in the matrix, while $\mathrm{Cu}$ is part of a nanosegregated $\mathrm{FH}$ phase. Here we have extended this approach to the high- $z T \mathrm{XNiSn}$ and $\mathrm{X}_{0.5} \mathrm{X}^{\prime}{ }_{0.5} \mathrm{NiSn}$ parent materials. This has enabled the accurate determination of the experimental compositions, and of the multiphase behaviour that occurs in these samples. In addition, we also present a detailed thermoelectric property analysis of degenerately and non-degenerately doped XNiSn and $\mathrm{X}_{0.5} \mathrm{X}^{\prime}{ }_{0.5} \mathrm{NiSn}$ compositions.

\section{Experimental}

The synthesis of the $\mathrm{XNiSn}$ and $\mathrm{X}_{0.5} \mathrm{X}^{\prime}{ }_{0.5} \mathrm{NiSn}\left(\mathrm{X}, \mathrm{X}^{\prime}=\mathrm{Ti}, \mathrm{Zr}\right.$ or Hf) samples has been reported in ref. 25. Neutron powder diffraction data for these samples were collected on the upgraded POLARIS instrument at the ISIS facility, Rutherford Appleton Laboratory, UK. Powders were loaded into cylindrical sample cans and diffraction data were collected at room temperature for $300 \mu \mathrm{A}$ h proton beam current to the ISIS target, corresponding to $\sim 2$ hours neutron beam time. In addition, two samples were studied at elevated temperatures: TiNiSn (373 to $973 \mathrm{~K}$ in $100 \mathrm{~K}$ steps) and $\mathrm{Ti}_{0.5} \mathrm{Hf}_{0.5} \mathrm{NiSn}(293,473,673$ and $873 \mathrm{~K})$. The neutron scattering lengths are $b_{\mathrm{Ti}}=-3.4 \mathrm{fm}, b_{\mathrm{Zr}}=7.2 \mathrm{fm}, b_{\mathrm{Hf}}=7.7 \mathrm{fm}, b_{\mathrm{Ni}}=10.3 \mathrm{fm}$ and $b_{\mathrm{Sn}}=6.2 \mathrm{fm}$. Crystal structure refinement was by the Rietveld method using the GSAS suite of programs and the EXPGUI graphical interface. ${ }^{33,34}$ Profile function three for time-of-flight data in GSAS was used to fit the peak shape. The thermoelectric characterisation for these samples was reported in ref. 25 but no data fitting was undertaken in that study.

\section{Results}

\section{Room temperature structures}

A convenient way to view the XNiSn half-Heusler structure is as a face-centred-cubic lattice of $\mathrm{Sn}$, where all the octahedral holes are occupied by $\mathrm{X}$ and half the tetrahedral holes (herein Y1) are filled with Ni. This leaves half the tetrahedral holes empty (Y2). The Y2 sites are fully occupied in the Heusler structure, leading to an increase in space group symmetry (from $F \overline{4} 3 m$ to $F m \overline{3} m$ ) and lattice parameter $(\Delta a \sim 0.2 \AA)$. TiNiSn is semiconducting with strong hybridisation between $\mathrm{Ni}$ and $\mathrm{Sn}$ s- and p-orbitals, while the valence and conduction bands are formed by hybridisation of the $\mathrm{Ti}$ and Ni d-orbitals. ${ }^{35} \mathrm{TiNi}_{2} \mathrm{Sn}$ in contrast is metallic, ${ }^{35}$ and this difference in chemical bonding is responsible for the absence of solid solution formation. ${ }^{36-42}$

TiNiSn, ZrNiSn and HfNiSn. The Rietveld fits to the POLARIS data are presented in Fig. 1. A single half-Heusler phase was used in the fits and the resulting lattice and atomic parameters are reported in Table 1 . These agree well with previously
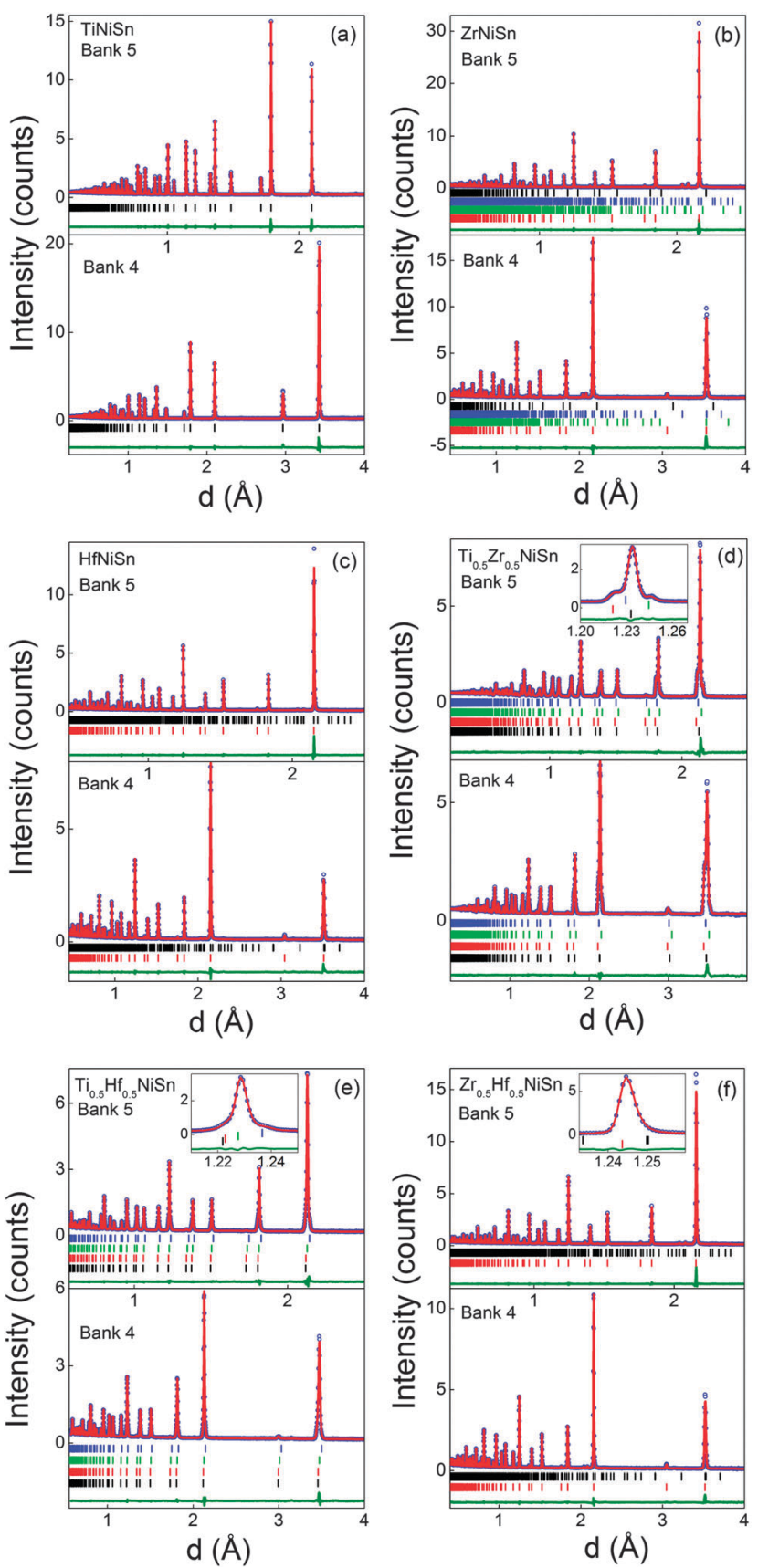

Fig. 1 Observed (circles), calculated (solid line) and difference Rietveld neutron powder diffraction profiles for (a) TiNiSn, (b) ZrNiSn, (c) HfNiSn, (d) $\mathrm{Ti}_{0.5} \mathrm{Zr}_{0.5} \mathrm{NiSn}$, (e) $\mathrm{Ti}_{0.5} \mathrm{Hf}_{0.5} \mathrm{NiSn}$ and (f) $\mathrm{Zr}_{0.5} \mathrm{Hf}_{0.5} \mathrm{NiSn}$. Bragg markers correspond to the half-Heusler phases used to fit the pattern (summarised in Tables 1 and 2), except for ZrNiSn where the markers are for ZrNiSn, $\mathrm{Zr}_{5} \mathrm{Sn}_{4}, \mathrm{Ni}_{2.67} \mathrm{Sn}_{2}$ and $\mathrm{ZrNi}_{2} \mathrm{Sn}$ (bottom to top). The insets in (d-f) illustrate the multiphase behaviour for samples with mixed $X$ metals. Bank 5 and 4 are the backscattering and 90 degrees detector banks, respectively. 
Table 1 Lattice parameter (a), fractional site occupancies (occ), thermal displacement parameters $\left(U_{\text {iso }} / \AA^{2}\right)$ and fit statistics for the XNiSn $(X=T i, Z r, H f)$ samples

\begin{tabular}{lllll}
\hline $\mathrm{X}$ & & $\mathrm{Ti}$ & $\mathrm{Zr}$ & $\mathrm{Hf}$ \\
\hline$a(\AA)$ & & $5.9298(1)$ & $6.1089(1)$ & $6.0795(1)$ \\
$\mathrm{X}$ & occ & 1 & 1 & 1 \\
& $U_{\text {iso }}$ & $0.00494(7)$ & $0.0057(2)$ & $0.0047(5)$ \\
$\mathrm{Ni}(1)$ & occ & 1 & 1 & 1 \\
& $U_{\text {iso }}$ & $0.00498(5)$ & $0.00461(6)$ & $0.0046(5)$ \\
$\mathrm{Ni}(2)$ & occ & $0.024(1)$ & $0.002(1)$ & $0.009(2)$ \\
& $U_{\text {iso }}$ & $0.00498(5)$ & $0.00461(6)$ & $0.0046(5)$ \\
$\mathrm{Sn}$ & occ & 1 & 1 & 1 \\
& $U_{\text {iso }}$ & $0.00407(5)$ & $0.0021(2)$ & $0.0036(5)$ \\
$\mathrm{wt} \%$ & & 100 & $95.00(8)$ & $99.17(3)$ \\
& & & & \\
$\chi^{2}$ & & 8.2 & 9.9 & 7.4 \\
$\mathrm{w} R_{\mathrm{p}} / \%$ & Bank 5 & 3.4 & 3.0 & 2.8 \\
& Bank 4 & 2.0 & 2.4 & 2.2 \\
$R_{\mathrm{p}} / \%$ & Bank 3 & 2.1 & 2.5 & 2.2 \\
& Bank 5 & 4.2 & 4.2 & 5.1 \\
& Bank 4 & 3.2 & 5.0 & 4.2 \\
$R_{\mathrm{f}}^{2} / \%$ & Bank 3 & 3.6 & 3.0 & 3.0 \\
& Bank 5 & 5.7 & 7.1 & 8.5 \\
& Bank 4 & 6.2 & 6.0 & 7.3 \\
& Bank 3 & 7.5 & 7.2 & 5.3
\end{tabular}

X: $4 \mathrm{a}(0,0,0), \mathrm{Ni}(1): 4 \mathrm{c}\left(\frac{1}{4}, \frac{1}{4}, \frac{1}{4}\right), \mathrm{Ni}(2): 4 \mathrm{~d}\left(\frac{3}{4}, \frac{3}{4}, \frac{3}{4}\right), \mathrm{Sn}: 4 \mathrm{~b}\left(\frac{1}{2}, \frac{1}{2}, \frac{1}{2}\right) . \mathrm{ZrNiSn}$ contains 0.93(7) wt\% $\mathrm{Zr}_{5} \mathrm{Sn}_{4}, 3.36(3) \mathrm{wt} \% \mathrm{Ni}_{2.67} \mathrm{Sn}_{2}$ and $0.44(1) \mathrm{wt} \%$ $\mathrm{ZrNi}_{2} \mathrm{Sn}$. HfNiSn contains $0.83(3) \mathrm{wt} \% \mathrm{HfO}_{2}$. Bank 5, 4 and 3 are the backscattering, 90 degrees and low angle detector banks, respectively.

reported values. ${ }^{25}$ Maintaining a stoichiometric TiNiSn model, with $\mathrm{Ti}, \mathrm{Ni}$ and $\mathrm{Sn}$ on their expected sites (X, Y1, Z), results in $\chi^{2}=8.8$. Two models were subsequently identified that resulted in an improvement in $\chi^{2}$. The first of these involves $2 \%$ excess $\mathrm{Ni}$ on the vacant tetrahedral Y2 site. The second model has $3 \%$ inversion of $\mathrm{Ti}$ and $\mathrm{Sn}$ (i.e. $\mathrm{Ti}_{0.97} \mathrm{Sn}_{0.03} \mathrm{NiSn}_{0.97} \mathrm{Ti}_{0.03}$ ). Both models produce $\chi^{2}=8.2\left(\chi^{2}=7.9\right.$ from a LeBail fit $)$. Larger degrees of inversion are needed for the previously reported $\mathrm{TiNi}_{1.04} \mathrm{Sn}\left(6 \%\right.$ inversion) and $\mathrm{TiNi}_{1.06} \mathrm{Sn}$ (10\% inversion) samples. ${ }^{7}$ A nominal TiNiSn 0.95 sample was also prepared by standard solid state reaction and best-fit models were found for $\mathrm{TiNi}_{1.056(2)} \mathrm{Sn}$ or $9 \%$ Ti-Sn inversion. Furthermore, HfNiSn requires 30\% inversion of $\mathrm{Hf}$ and $\mathrm{Sn}$, or $<1 \%$ excess Ni. ZrNiSn was found to be stoichiometric despite the presence of $\mathrm{Zr}_{5} \mathrm{Sn}_{4}$ and $\mathrm{Ni}_{2.67} \mathrm{Sn}_{2}$ secondary phases. The much smaller variation in $\mathrm{Y} 2$ site occupancies suggests that the presence of excess $\mathrm{Ni}$ is the most plausible interpretation of our data. This is in keeping with the covalent bonding in these structures and the large energetic cost for $\mathrm{X} / \mathrm{Sn}$ inversion. ${ }^{39}$

$\mathbf{T i}_{0.5} \mathbf{Z r}_{\mathbf{0 . 5}} \mathbf{N i S n}$. Our previous work demonstrated that the ingots with mixed $\mathrm{X}$ metals are not phase pure but contain multiple $\mathrm{X}_{1-x} \mathrm{X}_{x}^{\prime} \mathrm{NiSn}$ half-Heusler phases. ${ }^{25} \mathrm{~A}$ total of 4 halfHeusler phases were used to fit the NPD data, as shown in the inset to Fig. 1d. The lattice and atomic parameters for the 4 phases are presented in Table 2 . The $\mathrm{Zr}$ content of each phase was calculated from the lattice parameters using Vegard's law $\left(x_{\mathrm{V}}\right)$ and by refining the X-site occupancy $\left(x_{\mathrm{R}}\right)$. It was not possible to determine $x_{\mathrm{R}}$ for the most minor phase, present at $3 \mathrm{wt} \%$, and the occupancies were kept fixed at the $x_{\mathrm{V}}$ values. The $x_{\mathrm{R}}$ values are plotted against $x_{\mathrm{V}}$ in Fig. $2 \mathrm{a}$. From this figure, it may be seen that, for $x_{\mathrm{V}} \geq 0.5$, there is good agreement between $x_{\mathrm{R}}$ and $x_{\mathrm{V}}$. At lower values of $x_{\mathrm{V}}$ however, the refined $x_{\mathrm{V}}$ are somewhat larger than $x_{\mathrm{R}}$. This indicates a departure from Vegard's law with the $x_{\mathrm{R}}$ indicating a lower $\mathrm{Zr}$-fraction than that derived from the lattice parameter. This discrepancy does not lead to any significant difference in average composition of the multiphase samples. The highest resolution backscattering

Table 2 Lattice parameters (a), weight percentages (wt\%), fractional site occupancies (occ), thermal displacement parameters $\left(U_{i s o} / \AA^{2}\right), x_{V}$ calculated from Vegard's law, $X_{R}$ obtained from the refined $X$-site occupancies, compositional spread $(\Delta x)$, and fit statistics for the $X_{1-x} X^{\prime}{ }_{x} N i S n$ phases present in the $\mathrm{X}_{0.5} \mathrm{X}_{0.5}^{\prime} \mathrm{NiSn}$ samples $\left(\mathrm{X}, \mathrm{X}^{\prime}=\mathrm{Ti}, \mathrm{Zr}, \mathrm{Hf}\right)$

\begin{tabular}{|c|c|c|c|c|c|c|c|c|c|c|c|c|c|c|}
\hline$a(\AA)$ & wt $\%$ & & $\mathrm{X} / \mathrm{X}^{\prime}$ & $\mathrm{Ni}(1)$ & $\mathrm{Ni}(2)$ & Sn & $x_{\mathrm{V}}$ & $x_{\mathrm{R}}$ & $\Delta x$ & $\chi^{2}$ & Bank & $\mathrm{w} R_{\mathrm{p}}$ & $R_{\mathrm{p}}$ & $R_{\mathrm{f}}^{2}$ \\
\hline \multicolumn{15}{|c|}{$\mathrm{Ti}_{0.5} \mathrm{Zr}_{0.5} \mathrm{NiSn} /$ fitted composition: $\mathrm{Ti}_{0.495(7)} \mathrm{Zr}_{0.505(7)} \mathrm{Ni}_{1.028(3)} \mathrm{Sn}$} \\
\hline \multirow{2}{*}{$5.9815(2)$} & $18.3(2)$ & occ & $0.847(3) / 0.153(3)$ & 1 & $0.052(2)$ & 1 & $0.29(1)$ & $0.153(3)$ & $0.12(1)$ & 5.5 & & & & \\
\hline & & $U_{\text {iso }}$ & $0.0052(1)$ & $0.0052(1)$ & $0.0052(1)$ & $0.0052(1)$ & & & & & & & & \\
\hline \multirow[t]{2}{*}{$6.0240(2)$} & $19.7(7)$ & occ & $0.53(1) / 0.47(1)$ & 1 & $-0.003(8)$ & 1 & $0.5(1)$ & $0.47(1)$ & $0.10(1)$ & & 5 & 2.8 & 4.6 & 5.9 \\
\hline & & $U_{\text {iso }}$ & $0.00213(4)$ & $0.00213(4)$ & $0.00213(4)$ & $0.00213(4)$ & & & & & 4 & 1.6 & 2.9 & 3.6 \\
\hline \multirow[t]{2}{*}{$6.0406(1)$} & $59.2(7)$ & occ & $0.412(6) / 0.588(6)$ & 1 & $0.032(4)$ & 1 & $0.62(1)$ & $0.588(6)$ & $0.07(1)$ & & 3 & 1.7 & 2.9 & 5.4 \\
\hline & & $U_{\text {iso }}$ & $0.00653(4)$ & $0.00653(4)$ & $0.00653(4)$ & $0.00653(4)$ & & & & & & & & \\
\hline \multirow[t]{2}{*}{$6.1020(2)$} & $2.7(1)$ & occ & $0.04 / 0.96$ & 1 & 0 & 1 & $0.96(1)$ & 0.96 & $0.06(1)$ & & & & & \\
\hline & & $U_{\text {iso }}$ & $0.0010(2)$ & $0.0010(2)$ & $0.0010(2)$ & $0.0010(2)$ & & & & & & & & \\
\hline \multicolumn{15}{|c|}{$\mathrm{Ti}_{0.5} \mathrm{Hf}_{0.5} \mathrm{NiSn} /$ fitted composition: $\mathrm{Ti}_{0.53(1)} \mathrm{Hf}_{0.47(1)} \mathrm{Ni}_{1.019(5)} \mathrm{Sn}$} \\
\hline \multirow[t]{2}{*}{$5.9834(3)$} & 14(1) & occ & $0.805(5) / 0.195(5)$ & 1 & $0.030(4)$ & 1 & $0.36(1)$ & $0.195(5)$ & $0.12(1)$ & 6.0 & & & & \\
\hline & & $U_{\text {iso }}$ & $0.0050(2)$ & $0.0050(2)$ & $0.0050(2)$ & $0.0054(2)$ & & & & & & & & \\
\hline \multirow[t]{2}{*}{$6.0046(3)$} & $23(1)$ & occ & $0.46(2) / 0.54(2)$ & 1 & $0.00(2)$ & 1 & $0.50(1)$ & $0.54(2)$ & $0.04(1)$ & & 5 & 2.0 & 2.7 & 1.8 \\
\hline & & $U_{\text {iso }}$ & $0.00524(5)$ & $0.00524(5)$ & $0.00524(5)$ & $0.00524(5)$ & & & & & 4 & 1.5 & 2.6 & 4.8 \\
\hline \multirow[t]{2}{*}{$6.0157(1)$} & $60.1(9)$ & occ & $0.419(9) / 0.581(9)$ & 1 & $0.024(6)$ & 1 & $0.57(1)$ & $0.581(9)$ & $0.03(1)$ & & 3 & 2.0 & 2.5 & 2.8 \\
\hline & & $U_{\text {iso }}$ & $0.00524(5)$ & $0.00524(5)$ & $0.00524(5)$ & $0.00524(5)$ & & & & & & & & \\
\hline \multirow[t]{2}{*}{$6.0604(3)$} & $3.0(8)$ & occ & $0.13 / 0.87$ & 1 & 0 & 1 & $0.87(1)$ & 0.87 & $0.08(1)$ & & & & & \\
\hline & & $U_{\text {iso }}$ & $0.00007(7)$ & $0.00007(7)$ & $0.00007(7)$ & $0.00007(7)$ & & & & & & & & \\
\hline \multicolumn{15}{|c|}{$\mathrm{Zr}_{0.5} \mathrm{Hf}_{0.5} \mathrm{NiSn} /$ fitted composition: $\mathrm{Zr}_{0.59(4)} \mathrm{Hf}_{0.41(4)} \mathrm{Ni}_{1.002(3)} \mathrm{Sn}$} \\
\hline \multirow[t]{3}{*}{$6.0926(1)$} & $98.9(1)$ & occ & $0.59(4) / 0.41(4)$ & 1 & $0.002(3)$ & 1 & $0.49(1)$ & $0.59(4)$ & $0.14(1)$ & 10.9 & 5 & 2.1 & 4.4 & 6.0 \\
\hline & & $U_{\text {iso }}$ & $0.0066(2)$ & $0.00495(6)$ & $0.00495(6)$ & $0.0017(2)$ & & & & & 4 & 2.0 & 3.1 & 5.1 \\
\hline & & & & & & & & & & & 3 & 2.9 & 3.7 & 3.2 \\
\hline
\end{tabular}

$\mathrm{Zr}_{0.5} \mathrm{Hf}_{0.5} \mathrm{NiSn}$ contains 1.1(1) wt\% $\mathrm{Ni}_{2.67} \mathrm{Sn}_{2}$. 

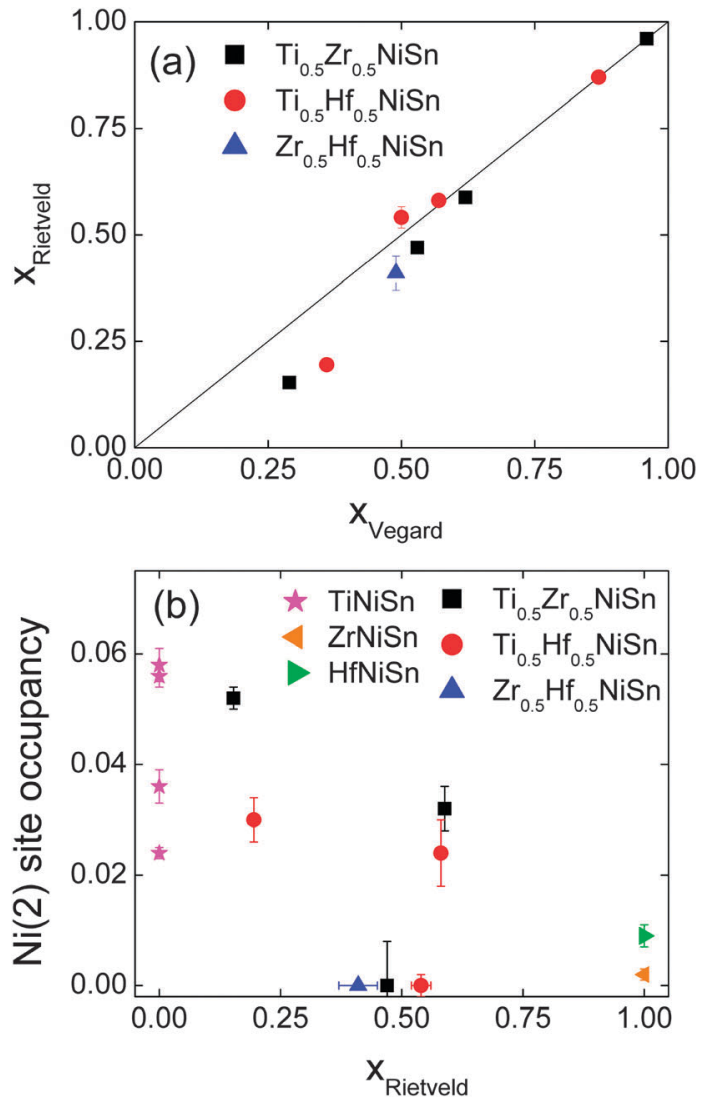

Fig. 2 (a) Fitted $X$-metal fractions $\left(x_{R}\right)$ against those calculated from Vegard's law $\left(x_{V}\right)(b) \mathrm{Ni}(2)$ site occupancy for the $X_{1-x} X_{x}{ }_{x} \mathrm{Ni}_{1+y} \mathrm{Sn}$ phases present in the $X_{0.5} X^{\prime}{ }_{0.5}$ NiSn samples $\left(X, X^{\prime}=T i, Z r, H f\right)$. Additional TiNiSn data from ref. 7.

detector (bank 5) was used to get an estimate of any peak broadening caused by further compositional fluctuations $(\Delta x) \cdot{ }^{25}$ All profile function parameters, except $\gamma_{1}$ which models microstrain, were kept fixed at the average value for the XNiSn end-members. For a cubic system, the microstrain can be easily related to a spread in $x$ value,${ }^{25}$ and the calculated values for $\Delta x$ are tabulated in Table 2 and are shown in Fig. 3a. Refinement of the Y2 site occupancy revealed that Ni partially occupies the $\mathrm{Y} 2$ site in 2 of the $4 \mathrm{HH}$ phases (Table 2). The largest excess of $\mathrm{Ni}$ $(y=0.052(2))$ was found in the phase with $x_{\mathrm{R}}=0.153(3)$. The average composition of this sample was found to be $\mathrm{Ti}_{0.495(7)} \mathrm{Zr}_{0.505(7)}$ $\mathrm{Ni}_{1.028(3)} \mathrm{Sn}$, which is in good agreement with the nominal $x$ value and indicates the presence of $3 \%$ excess Ni.

$\mathbf{T i}_{\mathbf{0 . 5}} \mathbf{H f}_{\mathbf{0 . 5}} \mathbf{N i S n}$. This sample shows similar multiphase behaviour to $\mathrm{Ti}_{0.5} \mathrm{Zr}_{0.5} \mathrm{NiSn}$ and was analysed analogously. The refined $\mathrm{Hf}$ occupancies were found to be $x_{\mathrm{R}}=0.195(5)$, $0.54(2), 0.581(9)$ and 0.87 , where the last value was fixed to $x_{\mathrm{V}}$ due to the low abundance of this phase. The $x_{\mathrm{R}}$ values are in good agreement with $x_{\mathrm{V}}$ for $x_{\mathrm{V}} \geq 0.5$, with a small discrepancy for lower $\mathrm{x}$, as seen for $\mathrm{Ti}_{0.5} \mathrm{Zr}_{0.5} \mathrm{NiSn}$ (Fig. 2a). The $\Delta x$ values are comparable to those found in $\mathrm{Ti}_{0.5} \mathrm{Zr}_{0.5} \mathrm{NiSn}$ and are shown in Fig. 3b. Two of the HH phases were found to contain Ni on the Y2 site. The refined values are presented in Table 2 and the $\mathrm{Ni}$ content is plotted in Fig. 2b. The average composition was found to be $\mathrm{Ti}_{0.53(1)} \mathrm{Hf}_{0.47(1)} \mathrm{Ni}_{1.019(5)} \mathrm{Sn}$.
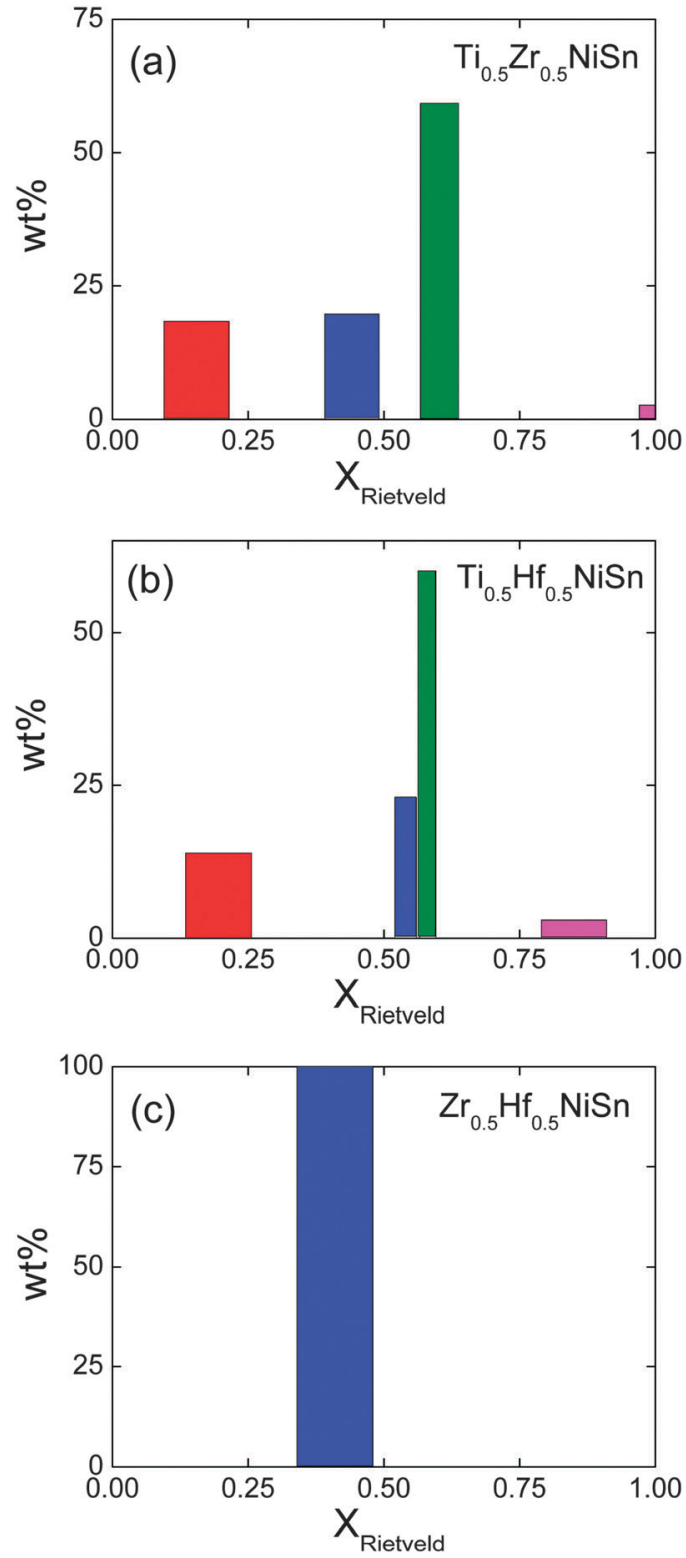

Fig. 3 Histograms of the phase distribution and compositional spread of the $X_{1-x} X^{\prime}{ }_{x} \mathrm{NiSn}$ phases present in the $X_{0.5} X^{\prime}{ }_{0.5} \mathrm{NiSn}$ samples $(X=\mathrm{Ti}, \mathrm{Zr}, \mathrm{Hf})$. The centre and widths of the bars correspond to $x_{\mathrm{R}}$ and $\Delta x$.

$\mathrm{Zr}_{\mathbf{0 . 5}} \mathbf{H f}_{\text {0.5 }} \mathbf{N i S n}$. The narrow range of unit cell parameters observed for this composition (due to the similar radii of $\mathrm{Zr}$ and Hf) means only one phase could be identified, instead of the three that were observable in the X-ray data (Fig. 1f). ${ }^{25}$ The lattice and atomic parameters are presented in Table 2. Refinement of the Y2 site occupancy suggested this sample is stoichiometric, and does not contain any excess $\mathrm{Ni}$. The final fitted composition of this sample was found to be $\mathrm{Zr}_{0.59(4)} \mathrm{Hf}_{0.41(4)} \mathrm{Ni}_{1.002(3)} \mathrm{Sn}$, consistent with the X-ray data, ${ }^{25}$ and the nominal composition.

\section{Temperature dependence studies}

TiNiSn. The fitted lattice parameters, fractional site occupancies and fit statistics are presented in Table 3 . The unit cell volume was found to increase linearly above $300 \mathrm{~K}$, as illustrated in Fig. 4a. 
The volume expansion could be fitted by $V(T)=V_{0}+A \operatorname{coth}\left(\theta_{\mathrm{D}} / T\right)$, where $A$ is a scale factor and $\theta_{\mathrm{D}}$ is the Debye temperature. From this fit $V_{0}=205.4(1) \AA^{3}, A=2.6(2)$ and $\theta_{\mathrm{D}}=347(22) \mathrm{K}$. This is consistent with literature values which put $\theta_{\mathrm{D}}$ in the range 360 $420 \mathrm{~K}^{43}$ The temperature dependence of the thermal displacement parameters $\left(U_{\text {iso }}\right)$ of each atom are plotted in Fig. $4 \mathrm{~b}$. The similar gradients and magnitudes indicate that all three atom types vibrate at around the same frequency. The values for $\mathrm{Sn}$ are slightly reduced compared with $\mathrm{Ti}$ and $\mathrm{Ni}$ due to its larger mass. Using the average slope and mass of TiNiSn a Debye temperature of 367(2) K was obtained, ${ }^{44}$ in excellent agreement with the value from the fit to cell volume, and the literature. The Ni occupancies on the Y1 and Y2 sites were also refined for each temperature step and remained constant within one estimated standard deviation (Table 3).

$\mathbf{T i}_{\mathbf{0 . 5}} \mathbf{H f}_{\mathbf{0 . 5}} \mathbf{N i S n}$. The fitted lattice parameters, weight fractions, site occupancies and fit statistics are presented in Table 4 . The lattice parameters for each phase were found to increase linearly with temperature. The increase in temperature was found to have very little effect on the distribution of the phases in this sample. The Ti:Hf ratio remained almost constant for each phase, while $\mathrm{Ni}(2)$ site occupancy was found to decrease somewhat at the highest measured temperatures. The weight fractions of each of the phases remained constant between 273 and $873 \mathrm{~K}$. The overall composition and distribution of phases therefore do not change significantly with temperature. The temperature dependence of the average thermal displacement parameters for the two most abundant phases was used to estimate the Debye temperature, which was calculated to be $317(2) \mathrm{K}$.

\section{Thermoelectric properties}

The use of band models to fit experimental thermoelectric data is increasingly common. The simplest of these models is the single parabolic band model which is most readily applied in the high temperature and degenerate semiconducting limit, ${ }^{45}$
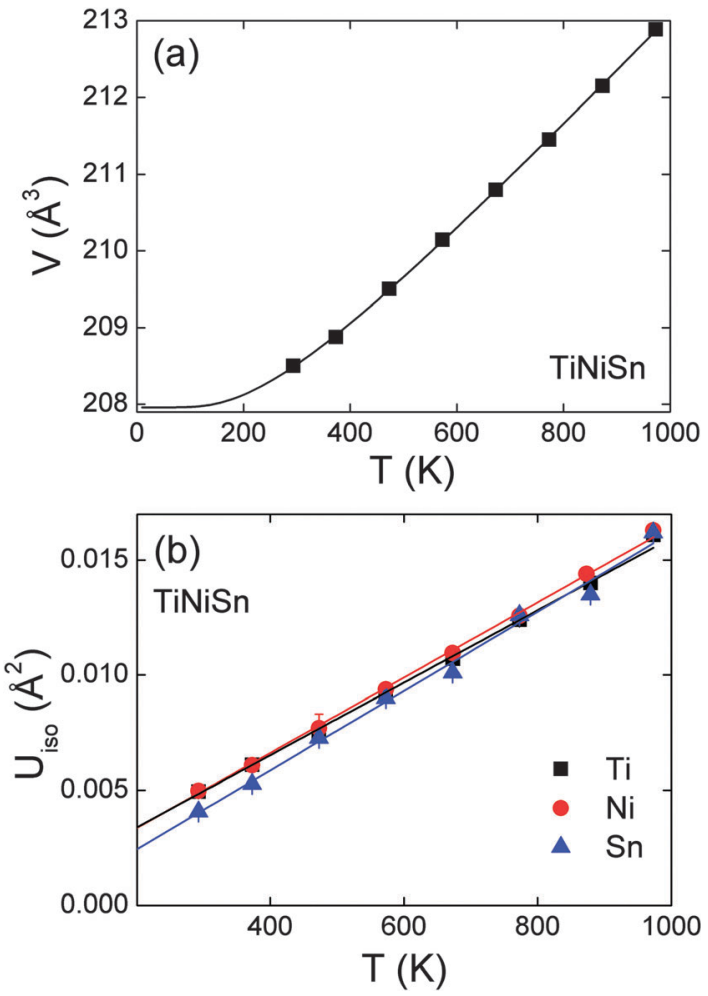

Fig. 4 (a) Temperature dependence of the unit cell volume for TiNiSn. The solid line is a fit (see manuscript text). (b) Temperature dependence of the thermal displacement parameters of $\mathrm{Ti}, \mathrm{Ni}$ and $\mathrm{Sn}$.

where the chemical carrier concentration $(n)$ is assumed constant. The $\rho(T)$ of electron doped $\mathrm{Ti}_{0.5} \mathrm{Zr}_{0.5} \mathrm{NiSn}_{1-z} \mathrm{Sb}_{z}$ samples $(z=0.005$, 0.01 and 0.02 ) is shown on a log-log plot in Fig. 5a. The slopes fall between $0.2-0.7$, where values between 1-1.5 are expected for electron transport limited by acoustic phonon scattering. The lower values observed here are characteristic of alloy scattering. ${ }^{45}$ As both acoustic and alloy scattering are energy independent, an

Table 3 Temperature evolution of the lattice parameter (a), thermal displacement parameters $\left(U_{\text {iso }} / \AA^{2}\right)$, Y2 site occupancy (occ) and fit statistics for TiNiSn between 293 and $973 \mathrm{~K}$

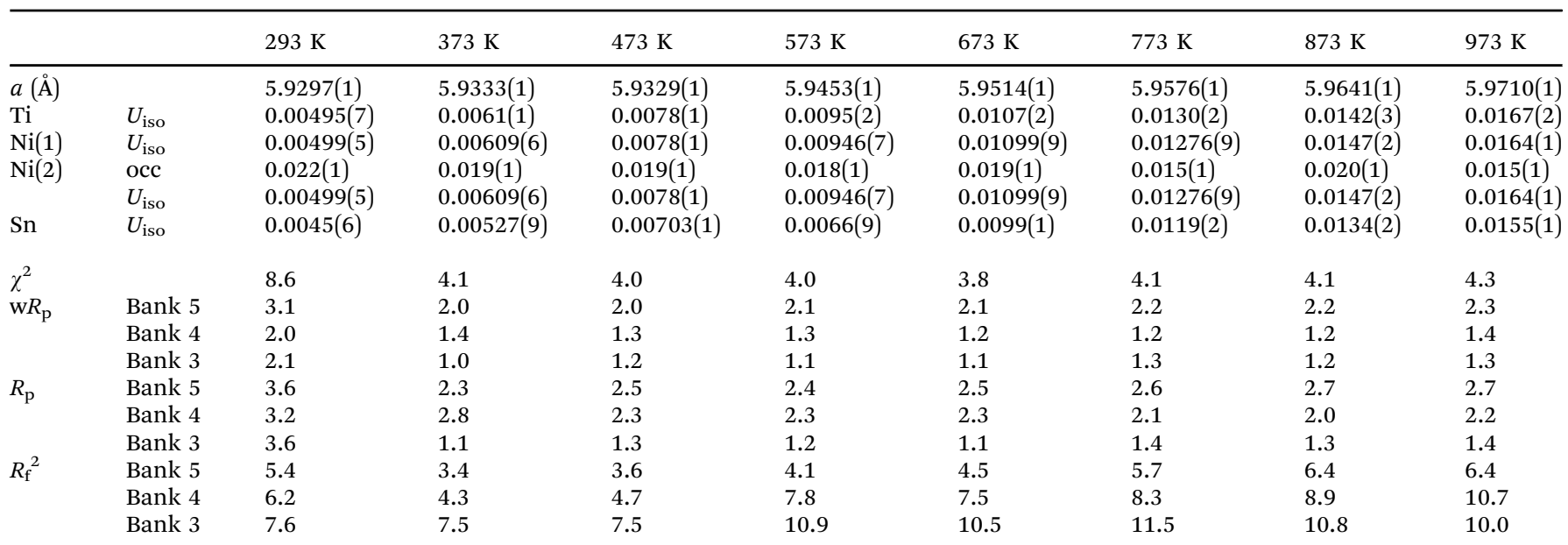

The $293 \mathrm{~K}$ pattern was collected outside of the furnace. 
Table 4 Temperature evolution of the lattice parameters (a), fitted $\mathrm{Hf}$ fractions $(x), \mathrm{Ni}(2)$ site occupancy, weight percentages $(w t \%)$, thermal displacement parameters $\left(U_{\text {iso }} / \AA^{2}\right)$ and fit statistics for the $\mathrm{Ti}_{1-x} \mathrm{Hf}_{x} \mathrm{NiSn}$ phases present in the $\mathrm{Ti}_{0.5} \mathrm{Hf}_{0.5} \mathrm{NiSn}$ sample

\begin{tabular}{|c|c|c|c|c|c|}
\hline \multicolumn{2}{|c|}{ Phase } & \multirow{2}{*}{$\frac{293 \mathrm{~K}}{5.9834(3)}$} & \multirow{2}{*}{$\frac{473 \mathrm{~K}}{5.9950(3)}$} & \multirow{2}{*}{$\frac{673 \mathrm{~K}}{6.0074(6)}$} & \multirow{2}{*}{$\frac{873 \mathrm{~K}}{6.0192(5)}$} \\
\hline 1 & $a(\AA)$ & & & & \\
\hline & $x$ & $0.195(5)$ & $0.223(5)$ & $0.210(9)$ & $0.206(8)$ \\
\hline & $\mathrm{Ni}(2)$ & $0.030(4)$ & $0.027(4)$ & $0.016(5)$ & $0.011(7)$ \\
\hline & $\mathrm{Wt} \%$ & $14(1)$ & $16(1)$ & $16(1)$ & $15.5(2)$ \\
\hline & $U_{\text {iso }}$ & $0.0050(2)$ & $0.0060(2)$ & $0.0088(2)$ & $0.0132(4)$ \\
\hline \multirow[t]{5}{*}{2} & $a(\AA)$ & $6.0046(3)$ & $6.0164(2)$ & $6.0285(3)$ & $6.0394(4)$ \\
\hline & $x$ & $0.54(3)$ & $0.559(9)$ & $0.57(1)$ & $0.59(2)$ \\
\hline & $\mathrm{Ni}(2)$ & $0.00(2)$ & 0 & 0 & 0 \\
\hline & $\mathrm{Wt} \%$ & $23(1)$ & $27.6(7)$ & 29.8(9) & $25.2(1)$ \\
\hline & $U_{\text {iso }}$ & $0.00524(5)$ & $0.00770(4)$ & $0.01068(5)$ & $0.01378(8)$ \\
\hline \multirow[t]{5}{*}{3} & $a(\AA)$ & $6.0157(1)$ & $6.0262(1)$ & $6.0378(1)$ & $6.0490(1)$ \\
\hline & $x$ & $0.581(9)$ & $0.588(4)$ & $0.610(5)$ & $0.592(6)$ \\
\hline & $\mathrm{Ni}(2)$ & $0.024(6)$ & $0.022(5)$ & 0 & 0 \\
\hline & $\mathrm{Wt} \%$ & $60.1(9)$ & $54.0(7)$ & $51.8(9)$ & $56.3(1)$ \\
\hline & $U_{\text {iso }}$ & $0.00524(5)$ & $0.00770(4)$ & $0.01068(5)$ & $0.01378(8)$ \\
\hline \multirow[t]{5}{*}{4} & $a(\AA)$ & $6.0604(3)$ & $6.0691(4)$ & $6.0800(4)$ & $6.0919(7)$ \\
\hline & $x$ & 0.87 & 0.87 & 0.87 & 0.87 \\
\hline & $\mathrm{Ni}(2)$ & 0 & 0 & 0 & 0 \\
\hline & $\mathrm{Wt} \%$ & $3.0(8)$ & $2.8(1)$ & $2.9(1)$ & $2.9(2)$ \\
\hline & $U_{\text {iso }}$ & $0.0001(3)$ & $0.0004(5)$ & $0.0021(6)$ & $0.0050(9)$ \\
\hline \multicolumn{2}{|c|}{ Current $^{a}$} & 450 & 200 & 200 & 75 \\
\hline$\chi^{2}$ & & 6.0 & 2.4 & 2.4 & 1.0 \\
\hline \multirow[t]{3}{*}{$\mathrm{w} R_{\mathrm{p}}$} & Bank 5 & 2.0 & 1.4 & 1.4 & 1.7 \\
\hline & Bank 4 & 1.5 & 1.0 & 1.3 & 1.4 \\
\hline & Bank 3 & 2.0 & 2.2 & 1.9 & 1.5 \\
\hline \multirow[t]{3}{*}{$R_{\mathrm{p}}$} & Bank 5 & 2.7 & 2.5 & 2.4 & 2.9 \\
\hline & Bank 4 & 2.6 & 1.6 & 2.8 & 3.3 \\
\hline & Bank 3 & 2.5 & 2.5 & 2.2 & 2.0 \\
\hline \multirow[t]{3}{*}{$R_{\mathrm{f}}^{2}$} & Bank 5 & 1.8 & 3.0 & 3.6 & 5.2 \\
\hline & Bank 4 & 4.8 & 8.8 & 9.8 & 7.0 \\
\hline & Bank 3 & 2.8 & 3.5 & 5.3 & 9.4 \\
\hline
\end{tabular}

identical $S(T)$ is expected, ${ }^{46}$ and the familiar expressions for $S$ and $n$ can be used:

$$
\begin{gathered}
S=\frac{k}{e}\left(\frac{2 F_{1}}{F_{0}}-\eta\right) \\
n=4 \pi\left(\frac{2 m^{*} k T}{h^{2}}\right)^{3 / 2} F_{1 / 2}
\end{gathered}
$$

Here, $k$ is Boltzmann's constant, $e$ the electron charge, $h$ is Planck's constant, $m^{*}$ is the effective carrier mass, $\eta$ is the reduced Fermi level measured from the conduction band mini$\operatorname{mum}\left(E_{\mathrm{F}} / k T\right)$, and $F_{j}$ are the Fermi integrals, which were evaluated numerically ( $\varepsilon$ is the reduced energy):

$$
F_{j}(\eta)=\int_{0}^{\infty} \frac{\varepsilon^{j} \mathrm{~d} \varepsilon}{1+\operatorname{Exp}[\varepsilon-\eta]}
$$

The magnitude of $S$ is therefore only a function of $\eta$ (eqn (1)), while $m^{*}$ can be evaluated using the $\eta$ value gained from the experimental $S$, and the chemical carrier concentration (eqn (2)). The calculated carrier concentrations were $\left(z=0.005,9.15 \times 10^{25} \mathrm{~m}^{-3}\right),(z=0.01$, $\left.1.83 \times 10^{26} \mathrm{~m}^{-3}\right)$ and $\left(z=0.02,3.66 \times 10^{26} \mathrm{~m}^{-3}\right)$ and the obtained $m^{*}$ values are $2.33 m_{\mathrm{e}}(z=0.005), 2.51 m_{\mathrm{e}}(z=0.01)$ and $2.64 m_{\mathrm{e}}$ $(z=0.02)$ where $m_{\mathrm{e}}$ is the electron mass. These values are in good agreement with published data for $\mathrm{ZrNi}_{1+y} \mathrm{Sn} \mathrm{HH}$ alloys. ${ }^{47,48}$ As a further test of the validity of the SPB model we calculated the predicted temperature dependence of $S$ using the constant carrier approximation, and these curves are plotted in Fig. 5b. There is a good agreement below $400 \mathrm{~K}$, while $S$ is overestimated above this temperature, which typically signals the presence of minority charge carriers. The $\rho(T)$ and $S(T)$ for the non-Sb doped (nondegenerate) samples containing Ti are shown in Fig. $5 \mathrm{c}$ and $\mathrm{d}$. The $\rho(T)$ follows a thermally activated temperature dependence over the entire measured temperature interval (300-730 K). The fitted bandgap values are $E_{\mathrm{g}}=0.12-0.15 \mathrm{eV}$ (see Table 5) which is much smaller than the $0.45 \mathrm{eV}$ gap predicted from first principles calculations. ${ }^{49}$ The observation of reduced bandgaps is common for $\mathrm{HHs},{ }^{50}$ and points towards the presence of in-gap states due to structural disorder and/or excess Ni. ${ }^{36}$ Similar bandgap values are observed for SPS processed $\mathrm{Ti}_{0.5} \mathrm{Zr}_{0.5} \mathrm{NiSn}$ samples, ${ }^{51}$ demonstrating that these values are not affected strongly by porosity. The $S(T)$ for these compositions shows a gradual monotonous decrease (Fig. 5d). By contrast, the $S(T)$ for samples containing $\mathrm{Zr}$ and $\mathrm{Hf}$ are characterised by a maximum near $350 \mathrm{~K}(\mathrm{X}=\mathrm{Zr})$ and $550 \mathrm{~K}\left(\mathrm{X}=\mathrm{Zr}_{0.5} \mathrm{Hf}_{0.5}, \mathrm{Hf}\right)$, followed by a rapid decrease (Fig. 5f). This rapid decrease is caused by the onset of minority carrier (p-type) conduction, which is also evident in the $\rho(T)$ data (Fig. 5e). The maximum for $\mathrm{X}=\mathrm{Zr}$ is lower than reported in the literature $(550 \mathrm{~K}),{ }^{52}$ and this may be linked to presence of impurity phases in this sample (Table 1). The $\ln \rho(T)-1 / T$ data for the samples without Ti are shown in Fig. 5e, and reveals the presence of similar bandgap values below the onset of minority carrier conduction $(0.07-0.16 \mathrm{eV}$, Table 5). In addition, the Goldsmid-Sharp formula was used to extract a value for the bandgap from the $S(T)$ data. ${ }^{53}$ These are larger and fall between 0.3-0.4 eV (Table 5). The discrepancy between the bandgap values from $\rho(T)$ and $S(T)$ data has recently been discussed and results from the mobility difference between electrons and holes, and leads to overestimates when using the classical Goldsmid-Sharp equation. ${ }^{50}$ The bandgap values observed here are consistent with recently reported values of $0.13 \mathrm{eV}$ for ZrNiSn from room temperature optical measurements. ${ }^{50}$

\section{Discussion}

There is now substantial evidence confirming that there is no solubility of excess $\mathrm{Ni}$ in the $\mathrm{HH}$ structure, and that segregation into a $\mathrm{HH}$ matrix and $\mathrm{FH}$ inclusions occurs. ${ }^{3,6}$ We have previously reported extensive electron microscopy characterisation of a $\mathrm{TiNi}_{1.05} \mathrm{Sn}$ sample which was prepared in an identical manner to the samples discussed here (e.g. by solid state reactions without post synthesis processing). ${ }^{18}$ This revealed that the excess $\mathrm{Ni}$ is finely dispersed within the matrix with a limit $<2 \mathrm{~nm}$ on the size of the nanoinclusions. We also demonstrated that $\sim 2 \%$ additional $\mathrm{Ni}$ was present in all $\mathrm{TiNiM}_{y} \mathrm{Sn}$ samples investigated. This was attributed to the stability of competing Ti-Sn binary phases. The observation 

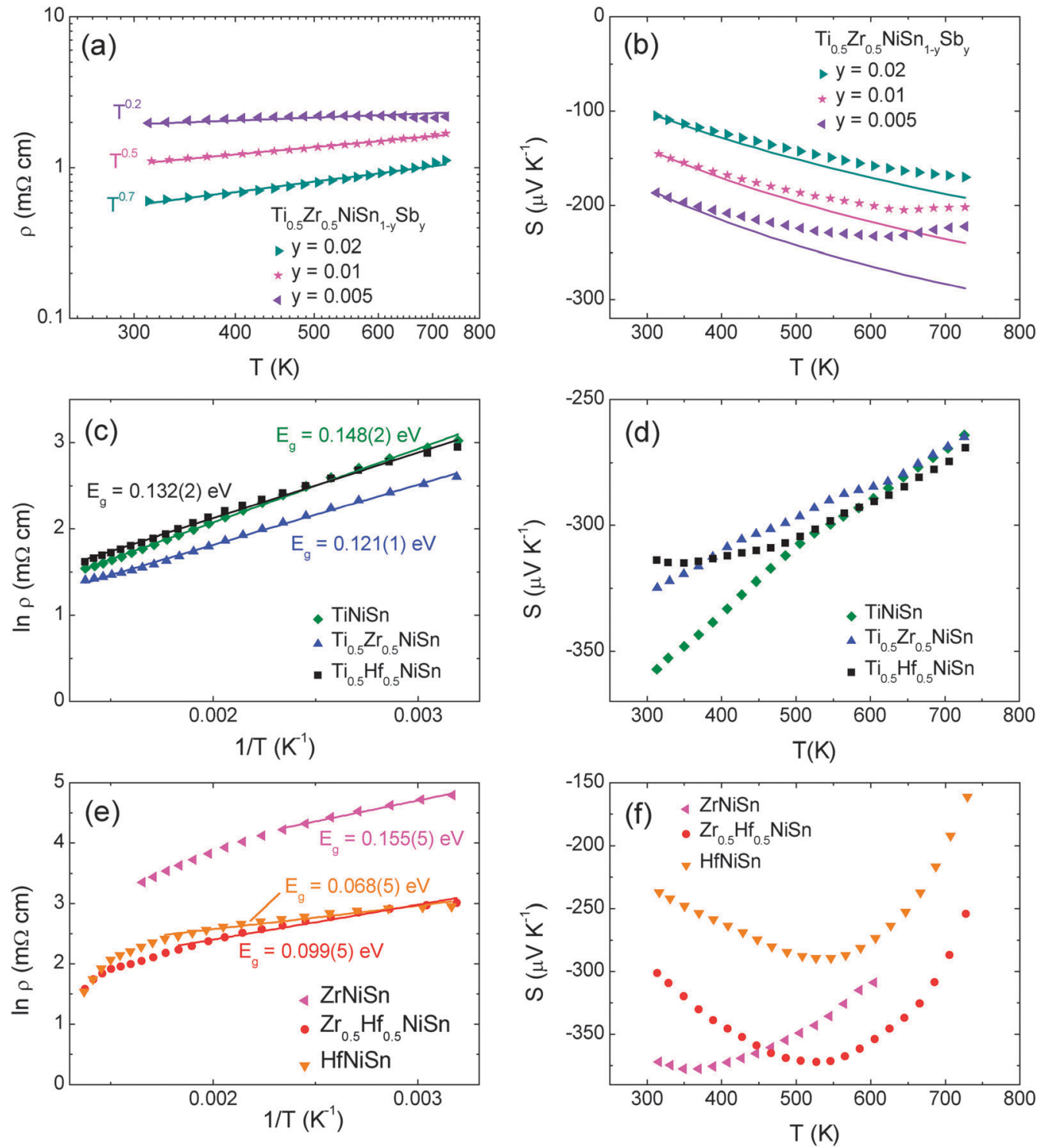

Fig. 5 Temperature dependence of the electrical resistivity and Seebeck coefficient for (a and b) degenerately doped Ti ${ }_{0.5} \mathrm{Zr}_{0.5} \mathrm{NiSn}_{1-z} \mathrm{Sb}_{z}(\mathrm{c}$ and d) nondegenerate XNiSn samples containing $\mathrm{X}=\mathrm{Ti}$ and (e and f) non-degenerate XNiSn samples with $\mathrm{X}=\mathrm{Zr}$, $\mathrm{Hf}$.

Table 5 Summary of bandgap values and pre-exponential factors obtained from fits to electrical resistivity data, and thermal bandgap values obtained using the Goldsmid-Sharp formula ${ }^{53}$

\begin{tabular}{|c|c|c|c|c|}
\hline Composition & $\begin{array}{l}\text { Fitting } \\
\text { range (K) }\end{array}$ & $E_{\mathrm{g}}(\mathrm{eV})$ & $\rho_{0}(\mathrm{~m} \Omega \mathrm{cm})$ & $E_{\mathrm{g}}=2 e\left|S_{\max }\right| T_{\max }$ \\
\hline TiNiSn & $300-730$ & $0.148(2)$ & $1.43(8)$ & \\
\hline $\mathrm{Ti}_{0.5} \mathrm{Zr}_{0.5} \mathrm{NiSn}$ & $300-730$ & $0.121(1)$ & $1.51(8)$ & \\
\hline $\mathrm{Ti}_{0.5} \mathrm{Hf}_{0.5} \mathrm{NiSn}$ & $300-730$ & $0.132(2)$ & $1.80(9)$ & \\
\hline ZrNiSn & $300-450$ & $0.155(5)$ & $13.7(2)$ & $0.271(8)$ \\
\hline $\mathrm{Zr}_{0.5} \mathrm{Hf}_{0.5} \mathrm{NiSn}$ & $300-570$ & $0.099(5)$ & $3.5(2)$ & $0.392(7)$ \\
\hline HfNiSn & $300-570$ & $0.068(5)$ & $6.0(2)$ & $0.310(5)$ \\
\hline
\end{tabular}

of $2-3 \%$ excess $\mathrm{Ni}$ for the samples containing $\mathrm{Ti}$, and the absence of excess Ni for samples with $\mathrm{X}=\mathrm{Zr}$, Hf (Tables 1 and 2), is in keeping with this earlier observation and emphasises the need for a tight control of the synthesis conditions. One of the most striking features of the transport data is the gradual decrease of $S(T)$ for samples containing $\mathrm{Ti}$, and the absence of an ambipolar transition (the onset of minority carrier conduction). This occurs for both TiNiSn and the multiphase samples, suggesting that the phase segregation has limited impact. Density functional theory calculations reveal similar bandstructures for $\mathrm{X}=\mathrm{Ti}, \mathrm{Zr}$ and $\mathrm{Hf}$ with an indirect gap of $\sim 0.45 \mathrm{eV}$ between the $\Gamma$ and $X$ points, ${ }^{49}$ and it is therefore not immediately apparent why $S(T)$ behaves differently. As the experimental bandgaps are also rather similar, it is tempting to link the absence of minority carrier conduction to the presence of electron doping from the $2-3 \%$ excess $\mathrm{Ni}$ in these samples. However, literature data reveals that the ambipolar transition survives in $\mathrm{ZrNi}_{1+y} \mathrm{Sn}$ samples with $6 \%$ excess $\mathrm{Ni},{ }^{47,52}$ suggesting that there may not be a link to the amount of excess $\mathrm{Ni}$, or that it may depend on the exact nature of the phase segregation. The $\mathrm{ZrNi}_{1+y} \mathrm{Sn}$ samples were prepared from the melt 
and it is likely that this will cause a difference in the degree of segregation of the $\mathrm{FH}$ phases. This can have a significant impact on the properties: for example the changes in $S(T)$ and $\rho(T)$ in the $\mathrm{TiNi}_{1+y} \mathrm{Sn}$ series with finely dispersed excess $\mathrm{Ni}$ are consistent with conventional doping, ${ }^{18}$ whereas enhancements in $S$ due to carrier filtering were observed in hot-pressed compositions containing well-defined $\mathrm{FH}$ inclusions. ${ }^{14}$ Further work is needed to fully elucidate the difference in behaviour between the samples that contain $\mathrm{Ti}$ and those that do not. Another plausible explanation is that the difference in behaviour is linked to a microstructural effect that only occurs in the presence of $\mathrm{Ti}$, and is not directly linked to either the multiphase behaviour or the presence of excess Ni. The $S(T)$ for degenerately doped $\mathrm{Ti}_{0.5} \mathrm{Zr}_{0.5} \mathrm{NiSn}_{1-z} \mathrm{Sb}_{z}$ samples can be modelled adequately using a single parabolic band model with the mobility limited by alloy scattering. The observation of carrier transport limited by alloy scattering is reasonable as the compositional changes due to phase segregation of the X-site metals occur over relatively large lengthscales $(>5 \mu \mathrm{m}) .^{20,21,25}$ These distances are greater than typical electron mean free paths, and are therefore not expected to impact strongly on the carrier transport.

Neutrons probe a larger sample volume than X-rays, and the phase distributions in the multiphase samples (Fig. 3) are significantly narrower than determined from X-ray data. The present data are more representative of the bulk, suggesting that 3-4 discrete phases are indeed present with the broadening of the individual $\mathrm{HH}$ X-ray and neutron profiles (quantified as $\Delta x$ ) at least partially due to microstrain effects and not solely linked to compositional variations. Some of the refined compositions fall outside of the thermodynamic limits for mixing of the X-metals, ${ }^{6}$ suggesting that the final observed phase distribution is kinetically controlled. The temperature-dependent neutron diffraction study into TiNiSn and $\mathrm{Ti}_{0.5} \mathrm{Hf}_{0.5} \mathrm{NiSn}$ showed no significant change in phase-distribution as the temperature was increased (Fig. 4, Tables 3 and 4). In addition to the temperature steps reported in Table 4 , this sample was held at $600{ }^{\circ} \mathrm{C}$ for 6 hours and re-measured at regular intervals. The reflections remained the same shape throughout, indicating no change in the distribution. In terms of application this highlights that these materials show stability to prolonged exposure to high temperatures, which is of vital importance for thermoelectric materials. The variable temperature data also afforded the extraction of a reliable estimate of the Debye temperatures for TiNiSn $\left(\theta_{\mathrm{D}}=367(2) \mathrm{K}\right)$ and $\mathrm{Ti}_{0.5} \mathrm{Hf}_{0.5} \mathrm{NiSn}\left(\theta_{\mathrm{D}}=317(2) \mathrm{K}\right)$.

The main conclusion is that XNiSn half-Heuslers samples are susceptible to phase segregation as exemplified by the presence of distinct half-Heusler compositions for samples with mixtures of $\mathrm{X}$ metals, and full-Heusler domains in samples containing Ti. The onset of minority carrier conduction observed for XNiSn samples with $\mathrm{Zr}$ and $\mathrm{Hf}$ is suppressed in the samples containing Ti.

\section{Acknowledgements}

The authors thank the EPSRC (grant EP/J000884/1 and EP/ K036408/1), and the STFC for the provision of neutron beam time at ISIS. D. A. MacLaren is acknowledged for scientific discussions and preliminary TEM data.

\section{References}

1 Thermoelectrics and its Energy Harvesting, ed. D. M. Rowe, CRC Press, Boca Raton, 2012.

2 H. Hohl, A. P. Ramirez, W. Kaefer, K. Fess, C. Thurner, C. Kloc and E. Bucher, Thermoelectric Materials - New Directions and Approaches, 1997, pp. 109-114.

3 J. W. G. Bos and R. A. Downie, J. Phys.: Condens. Matter, 2014, 26, 433201.

4 S. Chen and Z. F. Ren, Mater. Today, 2013, 16, 387-395.

5 W. J. Xie, A. Weidenkaff, X. F. Tang, Q. J. Zhang, J. Poon and T. M. Tritt, Nanomaterials, 2012, 2, 379-412.

6 Y. Kimura and Y. W. Chai, JOM, 2015, 67, 233-245.

7 R. A. Downie, D. A. MacLaren, R. I. Smith and J. W. G. Bos, Chem. Commun., 2013, 49, 4184-4186.

8 Y. W. Chai and Y. Kimura, Appl. Phys. Lett., 2012, 100, 033114.

9 Y. W. Chai and Y. Kimura, Acta Mater., 2013, 61, 6684-6697. 10 H. Hazama, M. Matsubara, R. Asahi and T. Takeuchi, J. Appl. Phys., 2011, 110, 063710.

11 C. S. Birkel, J. E. Douglas, B. R. Lettiere, G. Seward, N. Verma, Y. Zhang, T. M. Pollock, R. Seshadri and G. D. Stucky, Phys. Chem. Chem. Phys., 2013, 15, 6990-6997.

12 J. E. Douglas, C. S. Birkel, M.-S. Miao, C. J. Torbet, G. D. Stucky, T. M. Pollock and R. Seshadri, Appl. Phys. Lett., 2012, 101, 183902.

13 H. Hazama, R. Asahi, M. Matsubara and T. Takeuchi, J. Electron. Mater., 2010, 39, 1549-1553.

14 J. P. A. Makongo, D. K. Misra, X. Zhou, A. Pant, M. R. Shabetai, X. Su, C. Uher, K. L. Stokes and P. F. P. Poudeu, J. Am. Chem. Soc., 2011, 133, 18843-18852.

15 P. Sahoo, Y. Liu, J. P. A. Makongo, X.-L. Su, S. J. Kim, N. Takas, H. Chi, C. Uher, X. Pan and P. F. P. Poudeu, Nanoscale, 2013, 5, 9419-9427.

16 Y. Liu, P. Sahoo, J. P. A. Makongo, X. Zhou, S.-J. Kim, H. Chi, C. Uher, X. Pan and P. F. P. Poudeu, J. Am. Chem. Soc., 2013, 135, 7486-7495.

17 S. V. Faleev and F. Léonard, Phys. Rev. B: Condens. Matter Mater. Phys., 2008, 77, 214304.

18 R. A. Downie, R. I. Smith, D. A. MacLaren and J. W. G. Bos, Chem. Mater., 2015, 27, 2449-2459.

19 S. Sakurada and N. Shutoh, Appl. Phys. Lett., 2005, 86, 082105.

20 S. Populoh, M. H. Aguirre, O. C. Brunko, K. Galazka, Y. Lu and A. Weidenkaff, Scr. Mater., 2012, 66, 1073-1076.

21 M. Schwall and B. Balke, Phys. Chem. Chem. Phys., 2013, 15, 1868-1872.

22 E. Rausch, B. Balke, T. Deschauer, S. Ouardi and C. Felser, APL Mater., 2015, 3, 041516.

23 E. Rausch, B. Balke, S. Ouardi and C. Felser, Phys. Chem. Chem. Phys., 2014, 16, 25258-25262.

24 H. Y. Geng and H. Zhang, J. Appl. Phys., 2014, 116, 033708. 
25 R. A. Downie, D. A. MacLaren and J. W. G. Bos, J. Mater. Chem. A, 2014, 2, 6107-6114.

26 D. K. Misra, A. Bhardwaj and S. Singh, J. Mater. Chem. A, 2014, 2, 11913-11921.

27 D. K. Misra, A. Rajput, A. Bhardwaj, N. S. Chauhan and S. Singh, Appl. Phys. Lett., 2015, 106, 103901.

28 A. Bhardwaj and D. K. Misra, J. Mater. Chem. A, 2014, 2, 20980-20989.

29 W. J. Xie, Y. G. Yan, S. Zhu, M. Zhou, S. Populoh, K. Galazka, S. J. Poon, A. Weidenkaff, J. He, X. F. Tang and T. M. Tritt, Acta Mater., 2013, 61, 2087-2094.

30 W. J. Xie, J. He, S. Zhu, X. L. Su, S. Y. Wang, T. Holgate, J. W. Graff, V. Ponnambalam, S. J. Poon, X. F. Tang, Q. J. Zhang and T. M. Tritt, Acta Mater., 2010, 58, 4705-4713.

31 T. Graf, P. Klaer, J. Barth, B. Balke, H. J. Elmers and C. Felser, Scr. Mater., 2010, 63, 1216-1219.

32 J. E. Douglas, P. A. Chater, C. M. Brown, T. M. Pollock and R. Seshadri, J. Appl. Phys., 2014, 116, 163514.

33 A. C. Larson and R. B. Von Dreele, Los Alamos National Laboratory Report LAUR, 2000, pp. 86-748.

34 B. H. Toby, J. Appl. Crystallogr., 2001, 34, 210-213.

35 T. Graf, C. Felser and S. S. P. Parkin, Prog. Solid State Chem., 2011, 39, 1-50.

36 D. T. Do, S. D. Mahanti and J. J. Pulikkoti, J. Phys.: Condens. Matter, 2014, 26, 275501.

37 K. Kirievsky, Y. Gelbstein and D. Fuks, J. Solid State Chem., 2013, 203, 247-254.

38 K. Kirievsky, M. Shlimovich, D. Fuks and Y. Gelbstein, Phys. Chem. Chem. Phys., 2014, 16, 20023-20029.

39 P. Larson, S. D. Mahanti and M. G. Kanatzidis, Phys. Rev. B: Condens. Matter Mater. Phys., 2000, 62, 12754-12762.
40 V. V. Romaka, P. Rogl, L. Romaka, Y. Stadnyk, N. Melnychenko, A. Grytsiv, M. Falmbigl and N. Skryabina, J. Solid State Chem., 2013, 197, 103-112.

41 Y. V. Stadnyk and R. V. Skolozdra, Inorg. Mater., 1991, 27, 1884-1885.

42 J. E. Douglas, C. S. Birkel, N. Verma, V. M. Miller, M.-S. Miao, G. D. Stucky, T. M. Pollock and R. Seshadri, J. Appl. Phys., 2014, 115, 043720.

43 P. Hermet, K. Niedziolka and P. Jund, RSC Adv., 2013, 3, 22176-22184.

44 B. C. Sales, D. G. Mandrus and B. C. Chakoumakos, in Recent Trends in Thermoelectrics Materials Research II, ed. T. M. Tritt, Academic Press, San Diego, 2001, pp. 1-34.

45 A. F. May and G. J. Snyder, in Thermoelectrics and its Energy Harvesting, ed. D. M. Rowe, CRC press, Boca Raton, 2012.

46 W. Liu, H. Chi, H. Sun, Q. Zhang, K. Yin, X. Tang, Q. Zhang and C. Uher, Phys. Chem. Chem. Phys., 2014, 16, 6893-6897.

47 H. H. Xie, H. Wang, C. G. Fu, Y. T. Liu, G. J. Snyder, X. B. Zhao and T. J. Zhu, Sci. Rep., 2014, 4, 6888.

48 H. H. Xie, H. Wang, Y. Z. Pei, C. G. Fu, X. H. Liu, G. J. Snyder, X. B. Zhao and T. J. Zhu, Adv. Funct. Mater., 2013, 23, 5123-5130.

49 S. Ogut and K. Rabe, Phys. Rev. B: Condens. Matter Mater. Phys., 1995, 51, 10443.

50 J. Schmitt, Z. M. Gibbs, G. J. Snyder and C. Felser, Mater. Horiz., 2015, 2, 68-75.

51 R. A. Downie, S. R. Popuri, H. P. Ning, M. J. Reece and J. W. G. Bos, Materials, 2014, 7, 7093-7104.

52 H.-H. Xie, J.-L. Mi, L.-P. Hu, N. Lock, M. Chirstensen, C.-G. $\mathrm{Fu}$, B. B. Iversen, X.-B. Zhao and T.-J. Zhu, CrystEngComm, 2012, 14, 4467-4471.

53 H. J. Goldsmid and J. W. Sharp, J. Electron. Mater., 1999, 28, 869-872. 